\title{
Digging the dirt
}

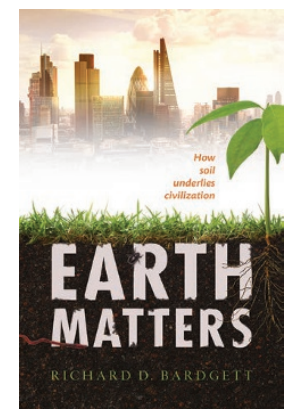

Earth Matters: How Soil Underlies Civilization by Richard D. Bardgett

OXFORD UNIV. PRESS: 2016. 224PP. E18.99

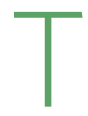
his relatively short book subtitled How Soil Underlies Civilization promises much and covers a great deal of ground. The author, Richard Bardgett, is a knowledgeable and entertaining guide. Over the course of the book, he travels from the northwest of England to Australian beaches, from Alpine glaciers to Burgundy vineyards, from city allotments and football pitches to battlefields, and from the primeval past to future prospects.

The first part of the book describes the genesis of soil - the geological, climatic and biological factors that drive its formation. It moves on to the importance of soil for crop productions and the causes of its degradation, including climate change and human intervention. There are sections on soil biodiversity and its importance for maintaining the functions essential for 'healthy' soil, and an explanation of how the myriad of different soil organisms with similar functions lead to the concept of 'redundancy' in soil. This means that organisms can substitute for one another to a certain extent but if a critical drop in diversity is reached, soil function becomes compromised. Several groups of mesofauna, fungi and bacteria with well-known functions involved in key soil processes are introduced. The list is far from comprehensive, perhaps understandable given the diversity of functions and a need to maintain brevity and accessibility in a short book. The application of metagenomics and metatranscriptomics to the soil microbiome is mentioned, but again, no details provided; anyone seeking more in-depth information on the vast diversity of the Bacteria, Archaea, Fungi, Protista and other Eukarya, including animals and plants, will need to consult a specialist tome. However, this is made easier because, unusually for a work of popular science, the book is very well referenced, citing the relevant scientific papers and specialist literature for those who want to know more.

The sections on soil and society, including crop production, amenity use, overuse, pollution and destruction by war, are thought-provoking. For example, although war can leave a toxic legacy of herbicide residues and radioactive substances, recovery from physical damage may be accelerated with help from earthworm activity. I had not previously seen discussion of 'Soil and the City'; this section provides fresh insights, such as the relatively improved quality of allotment garden soils compared to surrounding farmland, and, conversely, the detrimental consequences of sealing surfaces. Cement and asphalt are partly responsible for increasing temperatures and the risk of flooding in cities as they restrict adsorption of water. This was far more inspiring than a previous report I read on the importance of soils which described one major role as a substrate for car parks! City parks are known to provide places of tranquillity, reserves for wildlife and trees that improve air quality. Together with sports grounds, churchyards, allotments and domestic gardens, these green spaces constitute $60 \%$ of the area of London (and more in other major UK cities), providing a network of reservoirs for soil organisms. If the countryside was ruined and London flattened, at least the soil would have a chance of regenerating. On a more serious note, the link between the degradation of soil and the fall of civilizations has been well documented before but here the author places it in a contemporary context and also looks forward, with some trepidation, towards future problems increasing global populations place more pressure on soil for crop production, but climate change will likely accelerate soil deterioration, worsening greenhouse gas production. As with the more basic scientific sections, there are many pointers to more comprehensive academic studies.

One of the main topics covered by the book is the importance of soil for growing crops. Here, I must admit a personal interest - Rothamsted Research is cited as one of the originators of modern scientific agriculture in the nineteenth century. Feeding the ever-expanding global population is becoming a major problem. My personal view is that we must make use of the best available solutions, be they high-tech interventions or improved environmental management, to obtain a balance between crop yields and the maintenance of soil and environmental quality. These topics are mentioned in the book, but the author admits he is avoiding discussion of future sustainable crop production, on the grounds that it is extensively covered elsewhere. Nevertheless, I would have liked to have seen more of the debate since the need to protect soil quality and continue to grow crops, in light of food poverty and the devastating aftermath of war, are all topics covered by the book.

The personal comments in this book provide a fascinating insight into the author's scientific career and hopefully will inspire a new generation of soil scientists and soil ecologists, a group in imminent danger of extinction as acknowledged by the author. It is a positive sign that recent UK and international research priorities are seeking to reverse this decline.

Maybe this book should be compulsory reading for politicians and government officials responsible for environment and agriculture policies.

I don't know how far soil appeals to those who are not soil scientists, geologists, archaeologists, biologists, ecologists, farmers and growers, but a quick survey of my gardening acquaintances indicated considerable enthusiasm - they know the importance of soil, if not the science behind it. They will not be disappointed by the broad scope of the book and hopefully will be left wanting to know more. Unfortunately, the production lets the book down somewhat - the pictures are of poor quality and are not reproduced in colour which I feel is essential for illustrating, at the very least, the soil profile. There are also a few places where prose is repetitive and could have benefitted from more rigorous editing. However, overall, these minor gripes do not negate the value of this illuminating text.

\section{REVIEWED BY PENNY HIRSCH Penny Hirsch is a Principal Investigator at Rothamsted Research, Harpenden, Hertfordshire AL5 2JQ, UK. \\ e-mail:penny.hirsch@rothamsted.ac.uk}

